\title{
Pine weevils modulate defensive behaviour in response to parasites of differing virulence
}

\author{
Darragh E. Ennis ${ }^{1}$, Aoife B. Dillon ${ }^{2}$, Christine T. Griffin* \\ Department of Biology, National University of Ireland Maynooth
}

\section{A R T I C L E I N F O}

\section{Article history:}

Received 19 March 2010

Initial acceptance 16 April 2010

Final acceptance 4 May 2010

Available online 9 June 2010

MS. number: 10-00192R

\section{Keywords:}

antiparasite defence

entomopathogenic nematode

grooming

Heterorhabditis downesi

Hylobius abietis

large pine weevil

parasite avoidance

parasite recognition

Steinernema carpocapsae
Grooming and avoidance of contaminated areas are among the behavioural defences employed by animals against parasites. Antiparasite defence behaviour is costly in terms of time, energy and/or food foregone and therefore animals are expected to modulate their defences depending on the risk of attack and/or the severity of the symptoms caused. We tested the hypothesis that an insect host invests more in defence against more virulent (more likely to cause death) than less virulent parasites. We tested avoidance and grooming of adult pine weevils, Hylobius abietis, in response to infective juveniles of two species of entomopathogenic nematodes, the more virulent Steinernema carpocapsae and less virulent Heterorhabditis downesi. Weevils avoided feeding on a substrate contaminated with $S$. carpocapsae but not $H$. downesi. Weevils also groomed more when their bodies were contaminated with $S$. carpocapsae than either $H$. downesi or water. We also made direct observations of nematodes on weevils. When equal numbers of nematodes were applied to weevils more $S$. carpocapsae than $H$. downesi moved actively on the weevil's cuticle. Thus, the differential response of weevils to the two nematode species can be explained by the weevils detecting the more aggressive behaviour of $S$. carpocapsae than $H$. downesi, which corresponds to a higher probability of death.

(c) 2010 The Association for the Study of Animal Behaviour. Published by Elsevier Ltd. All rights reserved.
Most animals live in a world that is full of parasites. Since parasites frequently reduce host fitness (Price 1980), it is not surprising that animals have evolved numerous morphological, immunological and behavioural defences against them (Combes 2001). Hart (1990) recognized five behavioural strategies by which animals protect themselves against parasites, of which avoidance is the first line of defence. Behaviours employed in parasite avoidance include measures to dislodge parasites from the host animal's surface, and actions that serve to remove the host from the vicinity of the parasite. Vertebrates remove ectoparasites by grooming, and avoid parasitic or biting flies in numerous ways, including running away, grouping and microhabitat selection (reviewed in Hart 1990, 1994; Combes 2001; Moore 2002). Insects have a similar suite of behaviours to defend against their arthropod enemies: removal of ectoparasites by grooming is shown by honeybees (Apis mellifera and A. cerana) and damselflies Ischnura verticalis (Peng et al. 1987; Baker \& Smith 1997; Boecking \& Spivak

\footnotetext{
* Correspondence: C. T. Griffin, Department of Biology, NUI Maynooth, Maynooth Co. Kildare, Ireland.

E-mail address: christine.griffin@nuim.ie (C.T. Griffin).

D. E. Ennis is at the Entomology Research Laboratory, Biology Department, Concordia University, 7141 Sherbrooke St. West, Montreal, Quebec H4B 1R6, Canada

2 A. B. Dillon is at Coillte Teoranta, Newtownmountkennedy, Co. Wicklow, Ireland.
}

1999; Leung et al. 1999), while evasive and aggressive behaviours may help protect against parasitoid attack (Gross 1993; Gentry \& Dyer 2002; Vincent \& Bertram 2010).

There are many more examples of defensive reactions against arthropod than against helminth parasites, although reactions to the latter have been observed. Ungulates avoid faeces and faecescontaminated grazing areas and this is assumed to reduce transmission of gastrointestinal parasites (Hutchings et al. 2001). Since they react similarly to faeces from parasitized and unparasitized animals, this appears to be a generalized avoidance of 'risky areas' likely to contain parasites (Cooper et al. 2000), rather than a direct response following detection of the parasites. On the other hand, fish and amphibians respond to the presence of helminths themselves: minnows, Pimephales promelas, learn to recognize and avoid trematode cercariae, using visual and chemical cues (James et al. 2008), while Bufo americanus tadpoles avoided cercariae of Echinostoma trivolvis without physical contact, presumably in response to chemical and/or vibrational cues (Rohr et al. 2009).

One possible explanation for the paucity of responses to helminths compared to arthropods is that helminth infective stages tend to be small relative to vertebrate hosts, making them more difficult to detect (Wisenden et al. 2009). In contrast, helminths are large relative to invertebrate hosts, and both slugs (Wilson et al. 1999) and insects respond to infective juveniles of their 
nematode parasites. Defensive reactions (grooming and evasion) to entomopathogenic nematodes (Steinernema spp. and Heterorhabditis spp.) are demonstrated by various insects including ants Solenopsis invicta (Drees et al. 1992), termites Zootermopsis angusticollis, Coptotermes formosanus and C. vastator (Mankowski et al. 2005; Wilson-Rich et al. 2007), beetle larvae Popillia japonica and Cyclocephala borealis (Schroeder et al. 1993; Gaugler et al. 1994; Koppenhöfer et al. 2000) and cockroaches Blattella germanica (Appel et al. 1993). Hart (1990) stipulated two requirements that must be met for a particular behaviour to be regarded as having a parasite control function: the parasite must reduce host fitness, and the antiparasite behaviour must protect animals from infection. Entomopathogenic nematodes have the potential to reduce host fitness to zero: aided by a bacterial symbiont, they normally kill their hosts within days of infection (Kaya \& Gaugler 1993). Grooming and evasion can both protect insects against these nematodes. The most commonly reported defensive behaviour by insects against entomopathogenic nematodes is grooming. Soldier Coptotermes that were groomed by workers to remove nematodes survived significantly longer than soldiers that were not groomed (Mankowski et al. 2005). Similarly, Japanese beetle, Popillia japonica, larvae brushed their bodies to remove nematodes, and this activity significantly reduced the rate of parasitism (Gaugler et al. 1994). Avoidance behaviour, including colony relocation or extension of tunnels away from contaminated areas, contributes to the difficulty of controlling ants and termites using entomopathogenic nematodes (Drees et al. 1992; Gouge 2002).

Since there are fitness costs associated with antiparasite behaviour, including direct energetic costs, indirect energetic costs associated with reduced feeding opportunities, and distraction from predator vigilance (Hart 1990), hosts are expected to adjust their behavioural response depending on the threat posed by the parasite (Hughes \& Cremer 2007). This is seen, for example, in mammals which respond to biting flies more than nonbiting ones (Moore 2002). Insects have been shown to differentiate between more and less virulent strains of fungal parasites both of themselves and of their crops (Little et al. 2006; Mburu et al. 2009). There was a correlation between virulence and repellency of entomopathogenic fungi for Macrotermes michaelseni; the termite's response to fungal strains was directly related to the potential harm these fungi can cause the insect (Mburu et al. 2009). Fungus-growing ants Trachymyrmex cf. Zeteki removed spores of the garden parasitic fungus Escovopsis, but removed fewer spores that had been killed by irradiation, where the threat of parasitism was reduced (Little et al. 2006). To our knowledge, there are no previous studies on plastic responses of hosts to helminth parasites. Entomopathogenic nematodes are a promising group in which to look for associations between virulence and host defensive behaviours, since (1) it is known that insects detect and respond to their presence; (2) species vary in their virulence and this can be measured, and (3) experiments are easily conducted in the laboratory. The biology and behaviour of entomopathogenic nematodes have been extensively reviewed (e.g. Kaya \& Gaugler 1993; Burnell \& Stock 1999; Lewis et al. 2006). The infective juvenile, a specialized third-stage juvenile, seeks out and enters insect hosts through the mouth, anus and spiracles, and through the intersegmental membranes in some hosts. Once in the haemocoel it releases its symbiotic bacteria from its intestine and, together, the nematode-bacterial complex kills the host.

In this study, we tested the hypothesis that adult pine weevils, Hylobius abietis, respond to the presence of entomopathogenic nematodes by grooming and/or avoidance of a contaminated substrate; that they respond differentially to different nematode species, and that they are more likely to respond to a more virulent than a less virulent species (Steinernema carpocapsae and
Heterorhabditis downesi, respectively; Girling et al. 2010). To understand what might cause differences in weevil response to different nematode species we also examined the behaviour of both nematode species on the body of the insect host.

\section{METHODS}

\section{Nematodes}

The nematodes, S. carpocapsae All and H. downesi K122, were cultured with late-instar larvae of the wax moth Galleria mellonella (Woodring \& Kaya 1988). Infective juveniles were stored in tap water (2000 infective juveniles/ml) at $9{ }^{\circ} \mathrm{C}$ and were used within $3-5$ weeks after emergence from the host cadaver. All experiments were repeated using different batches of infective juveniles.

\section{Insects}

Pine weevils develop in timber of recently killed conifers, such as stumps of felled trees. Adults emerge and feed on the bark and cambium of young trees. Although the adults feed above ground, they also spend much of their time resting or hiding at the soil surface (Nordlander 1987) where they would be exposed to edaphic pathogens including entomopathogenic nematodes. Adult pine weevils were collected from clearfelled coniferous forests in Ireland. They were stored for up to 4 weeks in ventilated boxes at $20^{\circ} \mathrm{C}$ and fed fresh conifer billets (short lengths of stem). Pine weevil adults live for several years (Leather et al. 1999) and survive well in the laboratory. Within an experiment, weevils were assigned to different treatments randomly, irrespective of sex.

\section{Grooming Response}

We applied 1000 infective juveniles of either S. carpocapsae or $H$. downesi in $5 \mu \mathrm{l}$ of water to a weevil's head region at the point closest to the top of the rostrum. Control weevils had $5 \mu \mathrm{l}$ of water applied to the same area. The insect was then placed in a petri dish, $15 \mathrm{~cm}$ in diameter, and observed continuously for $20 \mathrm{~min}$. We assigned the insect's behaviour to five mutually exclusive classes and recorded the number of incidences and the total length of time spent in each class, using the Observer software (Noldus Information Technology, Wageningen, The Netherlands). The behavioural classes were: (1) grooming head: the insect rubbed its head region with one or more of its legs; (2) grooming antennae: the insect rubbed its antennae with one or more of its legs; (3) grooming elytra: the insect rubbed its wing cases with one or more of its legs; (4) grooming legs: the insect rubbed one leg with another leg; (5) not grooming: the insect did not rub one part of its body against another.

Each insect (and nematode) was used once only. The experiment was run three times with 10 or 20 (depending on availability; total 50) insects per treatment. For each replicate we used a different culture batch of nematodes because culture batches of entomopathogenic nematodes may vary in behaviour and other attributes, even when cultured and stored using consistent protocols.

\section{Behaviour of Nematodes on Weevils}

We applied nematodes to weevils as above to investigate the behaviour of the nematodes on the weevils, although the number of nematodes was reduced to facilitate accurate recording. To prevent grooming, we restrained the weevil from moving its legs by wrapping its abdomen and thorax in several layers of laboratory film (Parafilm). We applied 100 infective juveniles of either 
S. carpocapsae or H. downesi in $1 \mu \mathrm{l}$ water to the head region of the restrained insect at the point nearest to the top of the rostrum. The insect was placed in a $9 \mathrm{~cm}$ petri dish and the head region was observed under a dissecting microscope at $\times 20$ magnification. Many of the infective juveniles remained clumped at the point where they were applied. Every $2 \mathrm{~min}$ for $20 \mathrm{~min}$ we recorded the number of infective juveniles outside this clump and the behaviour of each of these dispersed nematodes. Infective juvenile behaviour was assigned to one of four mutually exclusive classes: (1) standing: a nematode that had lifted over half of its body off the surface of the insect; (2) wriggling: a nematode that had more than half of its body length on the surface of the insect and was moving; (3) climbing: a nematode that had climbed off the surface of the insect on top of another nematode; (4) still: a nematode that was not moving on the surface of the insect.

No effort was made to keep track of individual nematodes from one behaviour scan to the next. We ran the experiment three times with 10 insects per treatment in each replicate.

\section{Food Choice Experiment}

In this choice experiment, each weevil was allowed free access to food on a nematode-contaminated and on a clean substrate. Plastic plant propagators $(240 \times 380 \mathrm{~mm})$ were filled with mosspeat compost to a depth of approximately $20 \mathrm{~mm}$. A $5.5 \mathrm{~cm}$ petri dish filled with compost was placed $10 \mathrm{~mm}$ from each end of the propagator. We applied nematodes (25000 infective juveniles of either S. carpocapsae or H. downesi in $1 \mathrm{ml}$ of water) to the surface of the compost in one of the dishes, and $1 \mathrm{ml}$ of water to the other dish. Two discs of bark (10 $\mathrm{mm}$ diameter) punched from freshly cut Sitka spruce, Picea sitchensis, billets using a metal corer were placed on the surface of the compost in each petri dish. One weevil was placed at the centre of each propagator which was then covered with a plastic lid. Propagators were placed in a controlled temperature room at $20^{\circ} \mathrm{C}$ under a $16: 8 \mathrm{~h}$ light:dark regime. After 2 days, we traced feeding scars on the bark discs onto transparent acetate sheets, digitized the images using a scanner and measured them using ImagePro image analysis software (Media Cybernetics, Bethesda, Maryland, U.S.A.). Where an insect did not feed, it was excluded from the analysis. The experiment was run three times for each nematode species, with 12 insects in each replicate.

\section{Statistical Analysis}

For the grooming experiment, time spent grooming by all weevils was analysed by a Kruskal-Wallis test, as was the frequency of grooming events for weevils that groomed. Data for time spent grooming by only those weevils that groomed were normalized by a $(\log (x+1))$ transformation prior to analysis by one-way ANOVA, and Tukey's pairwise comparison was used to separate treatment means. To compare the proportion of weevils that groomed we used chi-square tests; for post hoc testing we used the Bonferroni correction (alpha/number of comparisons). Data for the behaviour of the two nematode species on weevils were analysed using Mann-Whitney $U$ tests. For the feeding choice test, the amount of feeding (bark area consumed) on the nematode substrate was expressed as a percentage of the total feeding on both substrates for each weevil and analysed using a Wilcoxon one-sample signed-ranks test with the null hypothesis that $50 \%$ of the feeding was on the nematode substrate. Significance levels were taken to be where $P<0.05$. Analysis was carried out using Minitab 14 (Minitab Inc., State College, PA, U.S.A.).

\section{RESULTS}

\section{Grooming Response}

Weevils with $S$. carpocapsae applied to their heads groomed nearly four times longer than weevils with $H$. downesi and 36 times longer than the water-only controls (mean \pm SE: S. carpocapsae: $44.6 \pm 8.44 \mathrm{~s} ; H$. downesi: $11.3 \pm 2.53 \mathrm{~s}$; control: $1.23 \pm 0.58 \mathrm{~s}$; $N=50$ ). Differences between treatments in grooming time were highly significant (Kruskal-Wallis test: $H_{2}=54.54, P<0.001$ ). We next asked whether differences between treatments were due to different numbers of weevils grooming, and/or the length of time spent grooming by those individuals that did groom. Differences between the three treatments in the number of weevils that groomed were highly significant $\left(\chi_{2}^{2}=48.59, P<0.001\right)$. Each of the nematode treatments differed from the control, but there was
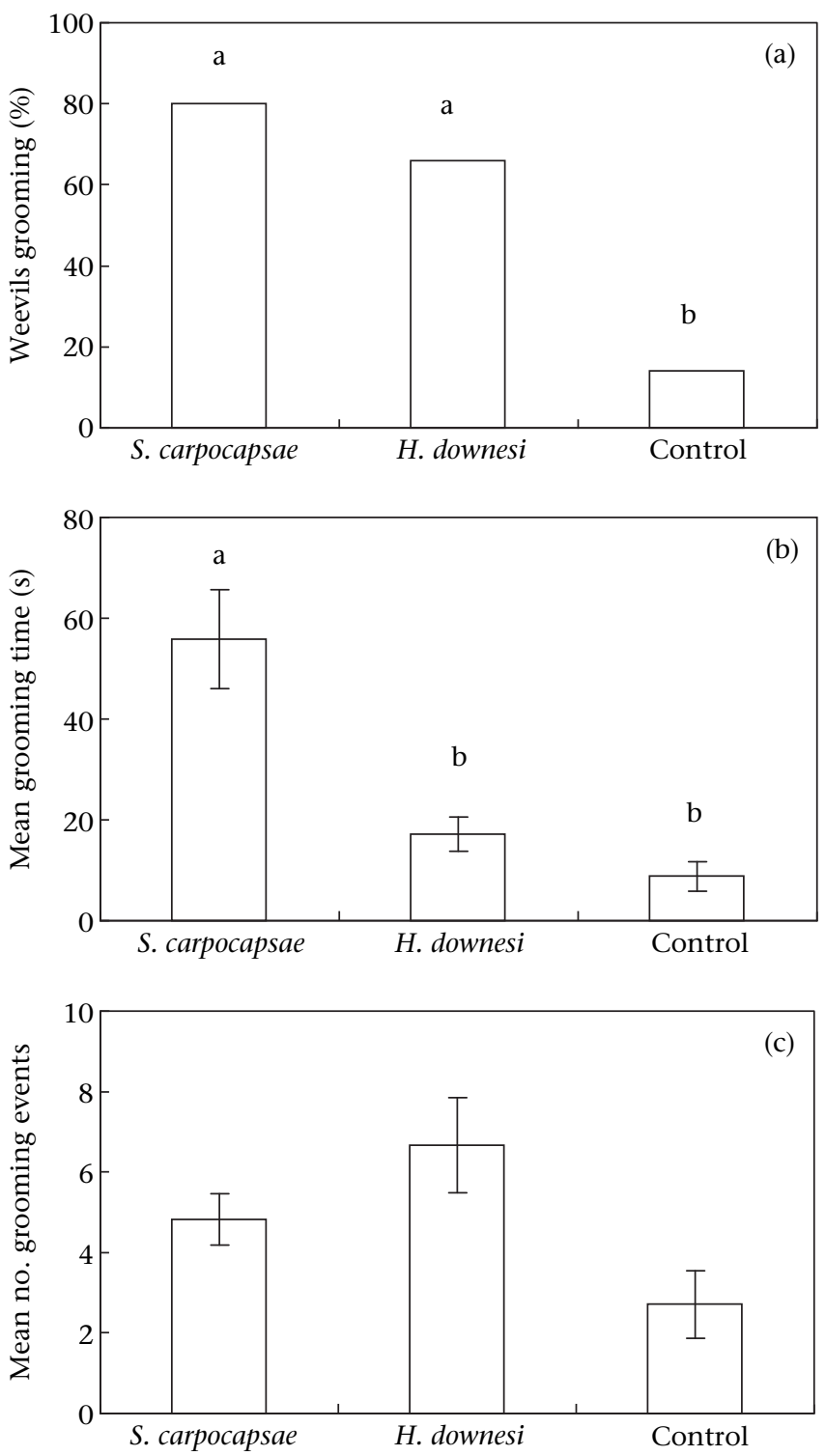

Figure 1. Grooming by adult Hylobius abietis with 1000 nematode infective juveniles (Steinernema carpocapsae or Heterorhabditis downesi) applied to the head region. Each weevil was observed for $20 \mathrm{~min}$. (a) Percentage of weevils that groomed $(N=50)$. (b) Time (mean \pm SE) spent grooming by each weevil that groomed. (c) Number (mean $\pm \mathrm{SE}$ ) of grooming events per weevil that groomed. Different lowercase letters indicate a significant difference between treatments: in (a) chi-square tests with a Bonferroni correction; in (b) Tukey's test: alpha $=0.05$. 


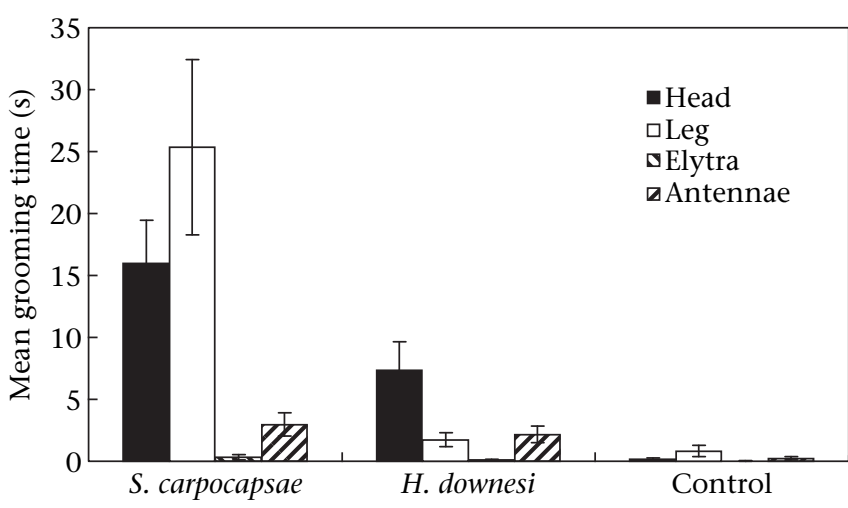

Figure 2. Mean \pm SE duration of grooming events by adult Hylobius abietis weevils after application of nematode infective juveniles (Steinernema carpocapsae or Heterorhabditis downesi) or water (control) to the weevil's head region. Each weevil $(N=50)$ was observed for $20 \mathrm{~min}$.

no difference between the two nematode treatments in the number of weevils that groomed (Fig. 1a). The amount of time spent grooming by each grooming insect was again influenced by treatment $\left(F_{2,77}=12.17, P<0.001\right)$, with $S$. carpocapsae-treated insects grooming for longer than the $H$. downesi treatment or control insects (Fig. 1b). There was no significant difference between treatments in the number of grooming events per grooming insect (Kruskal-Wallis test: $\mathrm{H}_{2}=3.10, P=0.212$; Fig. $1 \mathrm{c}$ ).

Insects treated with $S$. carpocapsae spent most time grooming their legs and head (Fig. 2). Grooming of the antennae was less common. Weevils treated with $H$. downesi spent most time grooming their head, followed by antennae and legs. Grooming of the elytra was the least common of the four grooming categories for both nematode species. In the control insects all grooming categories averaged less than $1 \mathrm{~s}$ each (Fig. 2).

\section{Behaviour of Nematodes on Weevils}

Nematodes applied to the head region began to disperse within $2 \mathrm{~min}$. By $20 \mathrm{~min}, 20.4 \pm 1.90 \mathrm{~S}$. carpocapsae and $17.6 \pm 1.73$ $H$. downesi infective juveniles per weevil had dispersed from the group; the difference between species was not significant $\left(t_{3}=0.90, P=0.46\right)$. The behaviour of these nematodes is shown in Fig. 3. Steinernema carpocapsae had more infective juveniles standing (Mann-Whitney $U$ test: $U=1194, \quad N_{1}=N_{2}=30$, $P<0.0001)$ and wriggling $(U=1112, P=0.004)$ while $H$. downesi had more infective juveniles that were still $(U=764, P=0.025)$.

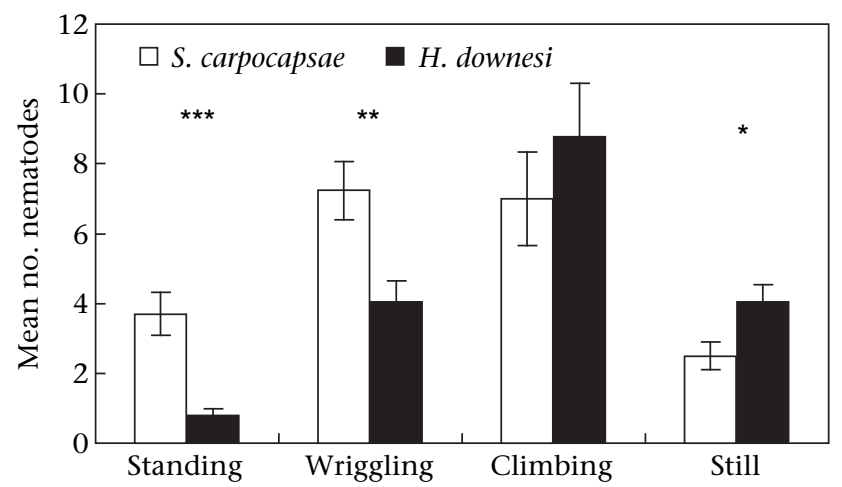

Figure 3. Behavioural classification of infective juveniles that left the application point on the head region of Hylobius abietis after $20 \mathrm{~min}$. Bars represent mean numbers $\pm \mathrm{SE}$. $N=30$ weevils for each treatment. Asterisks indicate a significant difference between treatments (Mann-Whitney test: ${ }^{*} P<0.05$; ${ }^{* *} P<0.01$; ${ }^{* * *} P<0.001$ ).

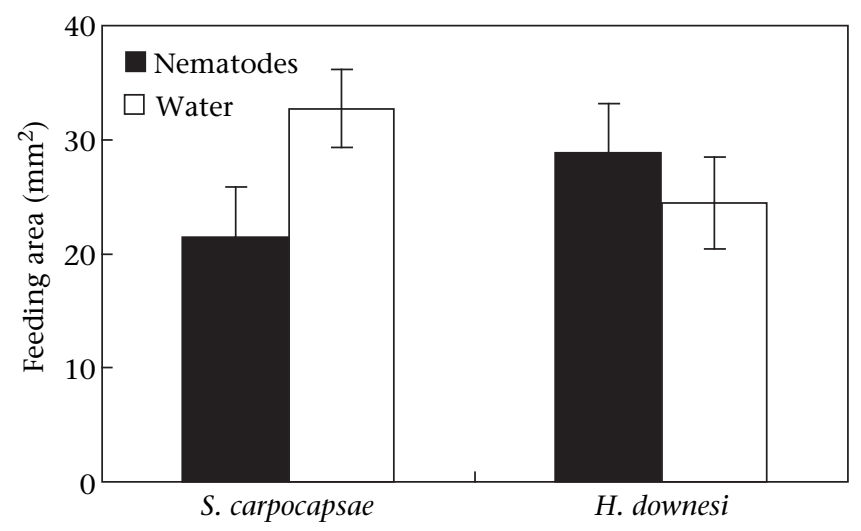

Figure 4. Mean $\pm \mathrm{SE}$ area of bark removed in a choice test by adult $H$. abietis from bark discs on a substrate that had been treated with nematodes or water. $N=33$ weevils for S. carpocapsae and 32 for $H$. downesi.

There was no significant difference between species in the number of nematodes that were climbing $(U=961, P=0.427)$.

\section{Food Choice Experiment}

Over 2 days, weevils removed less bark from discs on a substrate treated with $25000 \mathrm{~S}$. carpocapsae infective juveniles than from discs on a substrate without nematodes (mean \pm SE: nematode substrate: $21.5 \pm 4.41 \mathrm{~mm}^{2}$; no nematodes: $32.7 \pm 4.29 \mathrm{~mm}^{2}$; $N=33$; Fig. 4). There was little difference in the amount of bark removed when the choice was between bark on an $H$. downesi or on a nematode-free substrate (nematode substrate: $28.8 \pm 3.41 \mathrm{~mm}^{2}$; no nematodes: $24.5 \pm 4.05 \mathrm{~mm}^{2} ; N=32$; Fig. 4). Statistical analysis was carried out using feeding data for individual weevils; the null hypothesis was that weevils fed equally on bark on nematodecontaminated and uncontaminated substrates. Weevils took a lower proportion of their food (average: 30\%) from a substrate contaminated with $S$. carpocapsae than from a clean substrate, and the hypothesis of equal feeding on bark on each substrate was rejected (Wilcoxon signed-ranks test: $W=140, N=33, P=0.012$ ). There was no evidence for rejection of food on a contaminated substrate when the nematode was $H$. downesi (Wilcoxon signedranks test: $W=310, N=32, P=0.40$ ); in this case, $59 \%$ of food consumed was from the nematode treatment.

\section{DISCUSSION}

Adult pine weevils displayed two behavioural reactions to entomopathogenic nematodes: reduced feeding on a contaminated substrate in a choice test, and increased grooming when nematodes were on their bodies. There were marked differences in their response to the two nematode species tested: only $S$. carpocapsae caused food avoidance, and this species also had a much greater effect than $H$. downesi on grooming. More weevils groomed in response to both species but grooming insects groomed for longer than controls only when the infective juveniles were $S$. carpocapsae. Since $S$. carpocapsae killed twice as many adult pine weevils as $H$. downesi at an equivalent concentration under conditions in which behavioural avoidance was precluded (Girling et al. 2010), these findings support the hypothesis that hosts invest more in defence against more virulent parasites, but raise the question, how does the host recognize that a parasite is more virulent?

Antiparasite defensive behaviours presume that the host can detect the parasite (Wisenden et al. 2009), and a differential response to various parasites implies that the hosts can detect a difference (Mburu et al. 2009). Both S. carpocapsae and H. downesi 
moved actively over the insect cuticle when placed on it, and it is probable that the weevils detected the nematodes through touch, when moving nematodes stimulated tactile mechanoreceptors that clothe insect bodies (Gullan \& Cranston 2010). Japanese beetle larvae detected even a single live entomopathogenic nematode applied to their cuticle, and directed brushing and rubbing to the affected area (Gaugler et al.1994). In our experiment, nematodes on weevils showed differences in behaviour that could explain the differences in weevil grooming mentioned above. More S. carpocapsae than $H$. downesi moved actively on the surface of the insect, potentially providing a stronger stimulus. They were also more likely to raise themselves on their tails and wave in the air. The form of standing that is practised by ambush foragers such as $S$. carpocapsae, in which most of the body is raised from the surface, is known as nictating (Kondo \& Ishibashi 1986; Kaya \& Gaugler 1993) and is used to attach to a passing host. Continued nictation when already on a host, as seen here, may either indicate that the host has not been recognized as such, or that the infective juveniles are searching for cues to lead them to suitable areas on the insect through which to invade. However, nictation on a grooming insect could also lead to redistribution of the nematodes to the part of the body used in grooming, thus prolonging grooming. Weevils with $S$. carpocapsae on them spent at least as much time grooming their legs as their heads, in contrast to those with $H$. downesi which spent very little time grooming their legs. This could indicate that nematodes were picked up by a leg when grooming the head, on which the nematodes had been placed.

Differences in nematode behaviour could also explain the results of the feeding experiment, where weevils avoided feeding on a contaminated surface only when the contaminating nematodes were $S$. carpocapsae. As noted above, this species adopts an ambush strategy in its host finding, with infective juveniles tending to remain near the soil surface where they stand on soil particles and nictate. Periods of nictation facilitate attachment to a passing insect (Campbell \& Gaugler 1993) including adult pine weevils, which picked up considerably more $S$. carpocapsae than cruiseforaging Heterorhabditis megidis when moving across contaminated soil (Kruitbos et al. 2009). Cruise-foraging species such as H. megidis and $H$. downesi are expected to move into and through the soil in search of immobile hosts, rather than remain at the soil surface (Lewis et al. 1992; Campbell \& Gaugler 1997). It is likely that in the surface contamination experiment weevils again detected nematodes through tactile stimulation following contact, but we cannot rule out the possibility that weevils could see infective juveniles nictating on the soil surface. Cattle, Bos taurus, avoid ticks (but not nematodes) by sight (Hart 1994), and minnows avoid trematode cercariae, using visual and chemical cues (James et al. 2008).

The stronger antiparasitic behaviours observed in response to $S$. carpocapsae than to $H$. downesi is in line with our predictions that hosts should modulate their avoidance response in relation to parasite virulence. Termites were assumed to use a trait of the parasite that correlates directly with virulence to discriminate between more and less virulent entomopathogenic fungi (Mburu et al. 2009). Virulence in entomopathogenic nematodes has many components, operating both before and after invasion into the host (Thurston et al. 1994; Dowds \& Peters 2002). Variation after invasion can be attributed to virulence of the symbiotic bacteria, toxin production by nematodes, and evasion and suppression of the host immune response (Forst et al. 1997; Li et al. 2007). However, in order to kill, the nematodes must first find, recognize and enter the insect; so these aspects of nematode behaviour also make an important contribution to virulence (Gaugler et al. 1997; Lewis et al. 2006). We propose that the behaviour of $S$. carpocapsae (nictation on the soil surface and movement over the insect cuticle) both contributes to its greater virulence for adult pine weevils and makes it more apparent than $H$. downesi to the weevils. Although we used species from two different genera for our study, Steinernema and Heterorhabditis have acquired a similar suite of adaptations including behavioural and pathogenic traits through convergent evolution (Poinar 1993). Hypotheses concerning the adaptations of entomopathogenic nematodes frequently include members of both genera as representatives of the group (e.g. Kruitbos et al. 2010).

An understanding of insect responses to parasites may help in field deployment of entomopathogenic nematodes as biological insecticides. Pine weevils are a serious pest of reforestation throughout northern Europe (Leather et al. 1999), and nematodes are already used for population suppression by applying large numbers to stumps where the weevils develop (Dillon et al. 2006). Although adults are less susceptible to nematodes than earlier stages, treatment of seedlings to target adult $H$. abietis and related species has been contemplated (Pye \& Pye 1985; Eidt et al. 1995). Could behavioural deterrence help protect treated seedlings, encouraging the weevils to feed on alternative, noncrop, woody plants (Mansson \& Schlyter 2004)? In our experiment, S. carpocapsae influenced the feeding behaviour of weevils, 'protecting' the bark disc on the contaminated substrate, but the effect did not last beyond 2 days (data not shown). Since adult pine weevils can live for several years (Leather et al. 1999), their defensive behaviours including evasion and grooming are more likely to protect the insect than the plants.

Entomopathogenic nematodes are common in soils throughout the world (Hominick 2002) and most species appear to have relatively broad host ranges (Peters 1996). Natural populations have probably exerted strong selection pressure on soil-associated insects to evolve multiple defences (Villani et al. 1999). Hylobius abietis adults display each of the three levels of defence identified for insects by Gross (1993): (1) reduced probability of being found and contacted, as shown here by evasion of a contaminated surface; (2) behavioural and morphological defences, including typical thick cuticle of weevils and grooming as also shown here; and (3) physiological mechanisms to kill the parasites, including encapsulation (Girling et al. 2010). It is unclear which level is most important in protecting the weevils against entomopathogenic nematodes, but avoiding infection has advantages over strategies initiated after infection (Hart 1994), being relatively lower in cost (Poulin et al. 1999). Costs are further adjusted by the modulated response of the host to parasites posing varying threats.

\section{Acknowledgments}

The work was financially supported by the European Regional Development Fund (INTERREG IIIA) administered through the Welsh European Funding Office, and by the Irish National Development Plan through COFORD, the National Council for Forest Research and Development (ABATE project).

\section{References}

Appel, A. G., Benson, E. P., Ellenberger, J. M. \& Manweiler, S. A. 1993. Laboratory and field evaluations of an entomopathogenic nematode (Nematoda: Steinernematidae) for German cockroach (Dictyoptera: Blattellidae) control. Journal of Economic Entomology, 86, 777-784.

Baker, R. L. \& Smith, B. P. 1997. Conflict between antipredator and antiparasite behaviour in larval damselflies. Oecologia, 109, 622-628.

Boecking, O. \& Spivak, M. 1999. Behavioral defenses of honey bees against Varroa jacobsoni Oud. Apidologie, 30, 141-158.

Burnell, A. M. \& Stock, S. P. 1999. Heterorhabditis, Steinernema and their bacterial symbionts: lethal pathogens of insects. Nematology, 2, 31-42.

Campbell, J. F. \& Gaugler, R. 1993. Nictation behaviour and its ecological implications in the host search strategies of entomopathogenic nematodes (Heterorhabditidae and Steinernematidae). Behaviour, 126, 155-169. 
Campbell, J. F. \& Gaugler, R. 1997. Inter-specific variation in entomopathogenic nematode foraging strategy: dichotomy or variation along a continuum? Fundamental and Applied Nematology, 20, 393-398.

Combes, C. 2001. Parasitism: the Ecology and Evolution of Intimate Interactions. Chicago: University of Chicago Press.

Cooper, J., Gordon, I. J. \& Pike, A. W. 2000. Strategies for the avoidance of faeces by grazing sheep. Applied Animal Behaviour Science, 69, 15-33.

Dillon, A. B., Ward, D., Downes, M. J. \& Griffin, C. T. 2006. Suppression of the large pine weevil Hylobius abietis (L.) (Coleoptera: Curculionidae) in pine stumps by entomopathogenic nematodes with different foraging strategies. Biological Control, 38, 217-226.

Dowds, B. \& Peters, A. 2002. Virulence mechanisms. In: Entomopathogenic Nematology (Ed. by R. Gaugler), pp. 79-98. Wallingford: CAB International.

Drees, B. M., Miller, R. W., Vinson, S. B. \& Georgis, R. 1992. Susceptibility and behavioral response of red imported fire ant (Hymenoptera: Formicidae) to selected entomogenous nematodes (Rhabditida: Steinernematida and Heterorhabditidae). Journal of Economic Entomology, 85, 365-370.

Eidt, D. C., Zervos, S., Pye, A. E. \& Finney-Crawley, J. R. 1995. Susceptibility of adults of Hylobius congener Dalle Torre, Shenkling, and Marshall (Coleoptera: Curculionidae) to entomopathogenic nematodes. Canadian Entomologist, 127, 439-441.

Forst, S., Dowds, B., Boemare, N. \& Stackebrandt, E. 1997. Xenorhabdus and Photorhabdus spp: bugs that kill bugs. Annual Review of Microbiology, 51, 47-72.

Gaugler, R., Wang, Y. \& Campbell, J. F. 1994. Aggressive and evasive behaviors in Popillia japonica (Coleoptera: Scarabaeidae) larvae: defenses against entomopathogenic nematode attack. Journal of Invertebrate Pathology, 64, 193-199.

Gaugler, R., Lewis, E. \& Stuart, R. J. 1997. Ecology in the service of biological control: the case of entomopathogenic nematodes. Oecologia, 109, 483-489.

Gentry, G. L. \& Dyer, L. A. 2002. On the conditional nature of neotropical caterpillar defenses against their natural enemies. Ecology, 83, 3108-3119.

Girling, R. D., Ennis, D., Dillon, A. B. \& Griffin, C. T. 2010. The lethal and sublethal consequences of entomopathogenic nematode infestation for adult pine weevils, Hylobius abietis (Coleoptera: Curculionidae). Journal of Invertebrate Pathology, 104, 195-202. doi:10/1016/j.jip.2010.04.003.

Gouge, D. H. 2002. Applications for social insect control. In: Nematodes as Biocontrol Agents (Ed. by P. S. Grewal, R.-U. Ehlers \& D. I. Shapiro-Ilan), pp. 317-329. Wallingford: CABI Publishing.

Gross, P. 1993. Insect behavioral and morphological defenses against parasitoids. Annual Review of Entomology, 38, 251-273.

Gullan, P. J. \& Cranston, P. S. 2010. The Insects: an Outline of Entomology. Chichester: Wiley-Blackwell.

Hart, B. L. 1990. Behavioral adaptations to pathogens and parasites: 5 strategies. Neuroscience and Biobehavioral Reviews, 14, 273-294.

Hart, B. L. 1994. Behavioral defense against parasites: interaction with parasite invasiveness. Parasitology, 109, S139-S151.

Hominick, W. M. 2002. Biogeography. In: Entomopathogenic Nematology (Ed. by R. Gaugler), pp. 115-143. Wallingford: CABI Publishing.

Hughes, D. P. \& Cremer, S. 2007. Plasticity in antiparasite behaviours and its suggested role in invasion biology. Animal Behaviour, 74, 1593-1599.

Hutchings, M. R., Gordon, I. J., Kyriazakis, I. \& Jackson, F. 2001. Sheep avoidance of faeces-contaminated patches leads to a trade-off between intake rate of forage and parasitism in subsequent foraging decisions. Animal Behaviour, 62, 955-964.

James, C. T., Noyes, K. J., Stumbo, A. D., Wisenden, B. D. \& Goater, C. P. 2008. Cost of exposure to trematode cercariae and learned recognition and avoidance of parasitism risk by fathead minnows Pimephales promelas. Journal of Fish Biology, 73, 2238-2248.

Kaya, H. K. \& Gaugler, R. 1993. Entomopathogenic nematodes. Annual Review of Entomology, 38, 181-206.

Kondo, E. \& Ishibashi, N. 1986. Nictating behaviour and infectivity of entomogenous nematodes Steinernema spp., to the larvae of the common cutworm, Spodoptera litura (Lepidoptera: Noctuidae), on the soil surface. Applied Entomology and Zoology, 21, 553-560.

Koppenhöfer, A. M., Brown, I. M., Gaugler, R., Grewal, P. S., Kaya, H. K. \& Klein, M. G. 2000. Synergism of entomopathogenic nematodes and imidacloprid against white grubs: greenhouse and field evaluation. Biological Control, 19, 245-251.

Kruitbos, L. M., Heritage, S. \& Wilson, M. J. 2009. Phoretic dispersal of entomopathogenic nematodes by Hylobius abietis. Nematology, 11, 419-427.

Kruitbos, L. M., Heritage, S., Hapca, S. \& Wilson, M. J. 2010. The influence of habitat quality on the foraging strategies of the entomopathogenic nematodes Steinernema carpocapsae and Heterorhabditis megidis. Parasitology, 137, 303-309.

Leather, S. R., Day, K. R. \& Salisbury, A. N. 1999. The biology and ecology of the large pine weevil, Hylobius abietis (Coleoptera: Curculionidae): a problem of dispersal? Bulletin of Entomological Research, 89, 3-16.
Leung, B., Baker, R. L. \& Forbes, M. R. 1999. Grooming decisions by damselflies, age-specific colonisation by water mites, and the probability of successful parasitism. International Journal for Parasitology, 29, 397-402.

Lewis, E. E., Gaugler, R. \& Harrison, R. 1992. Entomopathogenic nematode host finding: response to host contact cues by cruise and ambush foragers. Parasitology, 105, 103-107.

Lewis, E. E., Campbell, J., Griffin, C., Kaya, H. \& Peters, A. 2006. Behavioral ecology of entomopathogenic nematodes. Biological Control, 38, 66-79.

Li, X. Y., Cowles, R. S., Cowles, E. A., Gaugler, R. \& Cox-Foster, D. L. 2007. Relationship between the successful infection by entomopathogenic nematodes and the host immune response. International Journal for Parasitology, 37, 365-374.

Little, A. E. F., Murakami, T., Mueller, U. G. \& Currie, C. R. 2006. Defending against parasites: fungus-growing ants combine specialized behaviours and microbial symbionts to protect their fungus gardens. Biology Letters, 2, 12-16.

Mankowski, M. E., Kaya, H. K., Grace, J. K. \& Sipes, B. 2005. Differential susceptibility of subterranean termite castes to entomopathogenic nematodes. Biocontrol Science and Technology, 15, 367-377.

Mansson, P. E. \& Schlyter, F. 2004. Hylobius pine weevils adult host selection and antifeedants: feeding behaviour on host and non-host woody scandinavian plants. Agricultural and Forest Entomology, 6, 165-171.

Mburu, D. M., Ochola, L., Maniania, N. K., Njagi, P. G. N., Gitonga, L. M. Ndung'u, M. W., Wanjoya, A. K. \& Hassanali, A. 2009. Relationship between virulence and repellency of entomopathogenic isolates of Metarhizium anisopliae and Beauveria bassiana to the termite Macrotermes michaelseni. Journal of Insect Physiology, 55, 774-780.

Moore, J. 2002. Parasites and the Behavior of Animals. Oxford: Oxford University Press.

Nordlander, G. 1987. A method for trapping Hylobius abietis (L.) with a standardised bait and its potential for forecasting seedling damage. Scandinavian Journal of Forest Research, 2, 199-213.

Peng, Y. S., Fang, Y. Z., Xu, S. Y. \& Ge, L. S. 1987. The resistance mechanism of the Asian honey bee, Apis cerana Fabr, to an ectoparasitic mite, Varroa jacobsoni Oudemans. Journal of Invertebrate Pathology, 49, 54-60.

Peters, A. 1996. The natural host range of Steinernema and Heterorhabditis spp. and their impact on insect populations. Biocontrol Science and Technology, 6 389-402.

Poinar, G. O. Jr. 1993. Origins and phylogenetic relationships of the entomophilic rhabditids, Heterorhabditis and Steinernema. Fundamental and Applied Nematology, 16, 333-338.

Poulin, R., Marcogliese, D. J. \& McLaughlin, J. D. 1999. Skin-penetrating parasites and the release of alarm substances in juvenile rainbow trout. Journal of Fish Biology, 55, 47-53.

Price, P. W. 1980. Evolutionary Biology of Parasites. Princeton, New Jersey: Princeton University Press.

Pye, A. E. \& Pye, N. L. 1985. Different applications of the insect parasitic nematode Neoaplectana carpocapsae to control the large pine weevil, Hylobius abietis. Nematologica, 31, 109-116.

Rohr, J. R., Swan, A., Raffel, T. R. \& Hudson, P. J. 2009. Parasites, info-disruption, and the ecology of fear. Oecologia, 159, 447-454.

Schroeder, P. C., Villani, M. G., Ferguson, C. S., Nyrop, J. P. \& Shields, E. J. 1993 Behavioral interactions between Japanese beetle (Coleoptera: Scarabaeidae) grubs and an entomopathogenic nematode (Nematoda: Heterorhabditidae) within turf microcosms. Environmental Entomology, 22, 595-600.

Thurston, G. S., Yule, W. N. \& Dunphy, G. B. 1994. Explanations for the low susceptibility of Leptinotarsa decemlineata to Steinernema carpocapsae. Biological Control, 4, 53-58.

Villani, M. G., Allee, L. L., Diaz, A. \& Robbins, P. S. 1999. Adaptive strategies of edaphic arthropods. Annual Review of Entomology, 44, 233-256.

Vincent, C. M. \& Bertram, S. M. 2010. Crickets groom to avoid lethal parasitoids. Animal Behaviour, 79, 51-56.

Wilson, M. J., Hughes, L. A., Jefferies, D. \& Glen, D. M. 1999. Slugs (Deroceras reticulatum and Arion ater agg.) avoid soil treated with the rhabditid nematode Phasmarhabditis hermaphrodita. Biological Control, 16, 170-176.

Wilson-Rich, N., Stuart, R. J. \& Rosengaus, R. B. 2007. Susceptibility and behaviora responses of the dampwood termite Zootermopsis angusticollis to the entomopathogenic nematode Steinernema carpocapsae. Journal of Invertebrate Pathology, 95, 17-25.

Wisenden, B. D., Goater, B. \& James, C. T. 2009. Behavioral defenses against parasites and pathogens. In: Fish Defenses Vol. 2: Pathogens, Parasites and Predators (Ed. by G. Zaccone, C. Perriere, A. Mathis \& B. G. Kapoor), pp. 151-168. Enfield, New Jersey: Science Publishers.

Woodring, J. L. \& Kaya, H. K. 1988. Steinernematid and Heterorhabditid Nematodes: a Handbook of Techniques. Fayetteville: Arkansas Agricultural Experimental Station. 